\title{
Una propuesta de pedagogía libertaria en bachillerato
}

\section{A proposal of libertarian pedagogy in baccalaureate}

Santiago Vargas Oliva

e-mail: santy.zizou@gmail.com

Universidad de Almería. España

\section{Resumen}

Este trabajo pretende exponer la puesta en marcha de una pedagogía libertaria en una clase de filosofía de $1 .^{\circ}$ de bachillerato dentro de un instituto español público. A través del estudio y análisis teórico de los elementos presentes en el anarquismo pedagógico, este proyecto pone en práctica esos principios basados en la autogestión y la colaboración con el fin de despertar en los alumnos el pensamiento crítico y creativo, así como la autonomía. Se trata de una propuesta de innovación en el aula, pero también de una reflexión sobre los problemas de la educación secundaria y la formación de ciudadanos libres protagonistas de su devenir. Las ideas que subyacen en el proyecto son un rescate o recuperación de las ideas filosóficas de autores como Freire, Kropotkin o Ferrer i Guardia adaptadas a estos tiempos, y una forma de réplica a la pedagogía neoliberal actual, basada en el rendimiento.

Palabras clave: Pedagogía libertaria; innovación; anarquismo; educación secundaria; autogestión.

\section{Abstract}

This work expects to explain the start-up of libertarian pedagogy in a philosophy class of the first course of a level within a Spanish public high school. Through the study and theoretic analysis of presented elements in the pedagogy anarchism this project puts into practice these principles based on the self-management and collaboration in order to awaken the students critical creative thought as well as the autonomy. It is about an innovation proposal in the classroom, and also a deep reflection abut secondary education problems ant the free citizen's training who are protagonists of their fate. The ideas underlying the project are a rescue or a recovery of philosophical ideas from authors such as Freire, Kropotkin and Ferrer I Guardia adapted to these times; a way of copy of the actual neoliberalism pedagogy, based on the performance.

Keywords: Libertarian pedagogy; anarchism; education; self-management.

Recibido / Received: 07-07-2018

Aceptado / Accepted: 22-11-2018

Cómo referenciar este artículo / How to reference this article:

Vargas Oliva, S. (2019). Una propuesta de pedagogía libertaria en bachillerato. Tendencias Pedagógicas, 33, 140-153. doi: 10.15366/tp2019.33.010 


\section{Justificación e introducción}

La sumisión a la autoridad tiene su fundamentación en la obediencia incondicionada a distintos agentes durante toda la trayectoria educativa. Esa premisa establecida tiene como solución de arreglo el desarrollo de la corriente pedagógica libertaria — anarquista—, que propugna una educación en libertad y carente de elementos de control y de coerción. Cuevas (2003) apunta que las teorías libertarias de la educación hace tiempo que perdieron vigencia en los círculos educativos, pero también señala que siguen estando ahí para quien quiera emprender un camino distinto con unos objetivos alternativos; y eso es lo que se propone este trabajo. El siguiente ensayo es una descripción detallada teórico-práctica de la adaptación y aplicación de una pedagogía libertaria en la puesta en marcha de una clase de filosofía para $10^{\circ}$ de Bachillerato. Si queremos alumnos librepensadores, apostemos por dotarlos de libertad en nuestras clases. Tomemos por bandera aquello que dijo el pedagogo Ricardo Mella: "la libertad se educa con libertad, la solidaridad con la solidaridad y la igualdad con la igualdad" (citado por García Moriyón, 1982, p. 399). De modo que este trabajo pretende ser un ensayo, un experimento de una propuesta práctica basada en la libertad como valor principal en la educación y una puesta en marcha de las teorías pedagógicas libertarias en el contexto actual. La forma de proceder para su desarrollo será la siguiente: iremos tratando las diferentes concreciones curriculares que engloban la propuesta llevada a los alumnos hasta llegar a las sesiones realizadas y los resultados obtenidos. Comenzaremos con la aproximación a la teoría pedagógica libertaria y la delimitación de los principios generales que la conforman ( $\mathbb{1} 1)$. En segundo lugar, abordaremos los elementos de la propuesta en relación con la legislación, con el centro y con la filosofía educativa propuesta (\$3). En último lugar, llegaremos hasta la práctica en el aula, la experiencia, los resultados y algunas actividades realizadas $(\mathbb{S} 0)$.

\section{Aspectos previos para la propuesta}

\subsection{La pedagogía libertaria: establecimiento de unas líneas generales}

Dentro de lo que se conoce como la pedagogía libertaria existe una gran variedad de teorías que se engloban dentro de esa corriente. La dificultad a la hora de tratarlas llevó a Silvio Gallo (1997) a hablar del paradigma anarquista en la educación como forma de discutir de todas esas teorías de una manera ecléctica. Tras la labor de investigación y lectura de ese paradigma, hemos esbozado cinco puntos comunes e irrenunciables que determinan la filosofía educativa de la pedagogía libertaria. Funcionarán como síntesis o ideario para conseguir un amplio bagaje que nos aporte herramientas teóricas para la práctica.

\subsubsection{Reflexión y rechazo: la educación nunca es neutral}

Como ya hemos dicho en el apartado anterior, todas las corrientes pedagógicas libertarias coinciden en la crítica al sistema1; de modo que, salvo excepciones, la educación es entendida bajo esta óptica como "un agente transformador", tal como lo veía el pedagogo brasileño Paulo Freire (1974, p. 85), una forma de lucha contra "la educación bancaria" en la que la "educación crítica" permite alcanzar la liberación de los hombres y las mujeres alienados (Ibíd., p. 88). Alumno y profesor deben concebirse, tal y como lo entendía Freire, como un "proyecto inacabado", aprendiendo juntos acerca de la realidad que los rodea (García, 2015, p. 39). Así, la educación se convierte en una "acción cultural" que puede ejercerse de dos maneras: 1) la acción cultural para la dominación y 2) la acción cultural para la liberación. Mientras la primera sería la imposición de la visión del mundo de quien oprime, a saber, la alienación de las masas, la segunda sería una acción de diálogo entre personas que "buscan significados reales" (Freire, 1975) y crean su propia conciencia. Dicho todo lo anterior, nos surge una pregunta que invita a/comporta una importante reflexión: ¿Toda educación es ideológica? Díaz y García (1980) son contundentes al respecto: “es

\footnotetext{
${ }^{1}$ Sin embargo, algunas posturas como la de Alexander Neil, manteniendo ese mismo enfoque de insatisfacción del alumnado dentro de la educación estatal, apuesta por una propuesta escapista (Díaz y García, 1980, p. 84) que no afronta los problemas sociales.
} 
ingenuo pensar que es posible una educación no manipuladora" (p. 66). Lo que exponen los autores de forma brillante en este ensayo es el desvelamiento de una de las grandes mentiras en cuanto a los procesos de enseñanza y aprendizaje, y esta falacia es que existe una información aséptica y objetiva que debe ser la única que se enseñe a los alumnos. Esto es lo que la LOMCE y sus tecnócratas proponen; y no hay nada más lejos de la realidad. En efecto, como prosiguen los autores, el hecho de no poner de manifiesto a sus alumnos que el conocimiento y los datos que reciben están manipulados, sesgados o condicionados por una época, una sociedad o por mediaciones manipuladoras "les incapacita para adoptar una postura crítica frente a dichas manipulaciones" (Ibíd.). La metodología de nuestra propuesta, alineada con este primer principio pedagógico, partirá del método crítico y dialógico de la realidad de Paulo Freire, del que hablaremos más tarde.

\subsubsection{Antiautoritarismo}

El control de la educación ha sido y seguirá siendo un objetivo prioritario por parte de los Estados. La práctica educativa en la escuela capitalista es una práctica encaminada a perpetuar las relaciones sociales tal y como existen en dicho momento histórico. Del mismo modo, las instituciones educativas son el lugar idóneo para que los futuros ciudadanos vayan interiorizando la sumisión a las situaciones de injusticia y opresión social de las que serán objeto en su edad adulta. Como indica Cuevas (2003), el antiautoritarismo libertario responde a la necesidad de "evitar la insumisión y desarrollar un aprendizaje de la autonomía y de la libertad" (p. 82). En esa misma línea, Ángel Cappelletti (2010) lo expresa del siguiente modo:

La base de toda pedagogía anarquista es, obviamente, la libertad. Toda coacción y toda imposición no sólo constituyen en sí mismas violaciones a los derechos del alumno, sino que también deforman su alma para el futuro y contribuyen a crear máquinas o esclavos en lugar de hombres libres (p. 27).

Asimismo, se suele hablar de dos tipos de autoridades, negativa y positiva; por un lado, la autoridad negativa es aquella que es fruto de las relaciones arbitrarias y con el objetivo principal de conseguir la sumisión de los educandos (cf. Cuevas, 2003, p. 82-83); por otro lado, la autoridad positiva proviene del reconocimiento moral de la sabiduría en pro de la ayuda para con el alumno (Ibíd.). De modo que lo que el docente se propone, en este segundo tipo de autoridad, es velar por que el alumno mantenga esa autonomía que le es inalienable, convertirse en un guía que se gana su reconocimiento por el interés que muestra en ellos, no en una jerarquía que se basa en una imposición basada en el premio o el castigo.

\subsubsection{Autogestión pedagógica}

El antiautoritarismo del que hemos hablado tiene como objetivo conseguir la autogestión democrática del aula. El pensador del siglo XIX William Godwin, por ejemplo, afirma que el docente debe (en pro/aras de formar ciudadanos libres) hacer notar lo menos posible su autoridad, realizando cada acción mediante pactos y consenso; además, propone que no debería existir ningún programa preestablecido, puesto que no estaría basado en ese grupo social concreto ni en las necesidades que éste tiene (cf. Tomassi, 1978, pp. 35-37). La autogestión pedagógica debe estar basada en la libre discusión entre alumnos y profesores (Godwin, 2005), lo cual quiere decir que esa autoridad del docente debe ser positiva (algo de lo que ya hemos hablado) y la piedra angular de la práctica libertaria debe ser, por encima de todo, la asamblea de miembros. La tergiversación del término «democracia», que proviene del griego, ha llegado también a la escuela. En la Grecia Antigua, en Atenas, la democracia significaba la participación de todos los ciudadanos en los asuntos públicos. Sin embargo, tras la modernidad, dicha práctica ha sido sustituida por los sistemas representativos; es decir, ya no se toman decisiones, sino que se elige a otros para que las tomen por nosotros. Así actúa también la escuela: todos toman decisiones por los profesores, y éstos las toman por los alumnos. Sin embargo, la asamblea de aula debe ser la piedra angular de la práctica libertaria, puesto que su soberanía garantiza que los alumnos y el docente (conjuntamente) están tomando las decisiones que les afectan. Sólo así, 
"mediante la organización social alcanzaremos la felicidad de todos" (Paniagua, 2008, pp. 12-15).

\subsubsection{La educación integral}

La filosofía anarquista cree que toda persona posee un gran potencial multidisciplinar, y toda persona tiene "derecho a desarrollar de la forma más completa todas sus facultades físicas e intelectuales" (Tomassi, 1978, p. 122).

Los alumnos tienen la necesidad de realizarse holísticamente como individuos; el mismo Bakunin consideraba que la práctica educativa debe "dar la posibilidad a cada uno, sea cual fuere su condición social, para que pueda realizarse completamente, en condiciones iguales para todo" (citado por Tomassi, 1978, p. 122). Max Stirner, por ejemplo, defendía con ahínco que la tarea del docente no debe ser la de instruir, sino la de, por encima de todo, "promover la creatividad para formar espíritus libres" (Ibíd., p. 73). La solución no es otra que evitar la parcelación de los educandos y fomentar ese espíritu creativo del que todos disponen.

\subsubsection{Colaboración}

La autogestión y la asamblea como pináculos de esta forma de entender la práctica educativa tienen una estrecha relación con la actitud colaborativa como forma de entender las relaciones dentro del aula. Desde este trabajo se enarbola ese lema de la Escuela Moderna de Ferrer i Guardia: "ni premios ni castigos" (2009, p. 128)2. Proponemos un verdadero cambio (apoyado en las ideas de muchos autores, sobre todo de Kropotkin) en el paradigma de las relaciones educativas, entendiendo que la competitividad y el individualismo egoísta deben ser sustituidos por una forma comunitaria de aprendizaje colaborativo basado en el principio "de cada cual su capacidad, a cada cual su necesidad" (Cuevas, 2003, p. 36; Cappelletti, 1978). De ese modo abordaremos, como podrá verse posteriormente, el problema de la evaluación, con la creación colectiva de un método sumativo-colaborativo previamente consensuado, procurando cumplir todos los principios libertarios: ausencia de autoridad negativa, autogestión, eclecticismo y cooperación.

\section{3. ¿Qué podemos hacer?}

\subsection{Un ensayo libertario: elementos presentes en la práctica}

El estudio y la reflexión previa llevados a cabo a través de la bibliografía y la investigación son del todo infructuosos si no los ponemos en práctica a través del proceso de enseñanza y aprendizaje en un aula. Así, las sesiones realizadas son un escenario idóneo para intentar esgrimir un paradigma de praxis libertaria basada en esos presupuestos sociales de los que partimos. Los siguientes subapartados funcionan a modo de guía intensiva para el seguimiento de la posterior explicación de lo planteado y sucedido en la práctica. Por decirlo de algún modo, todos los elementos que vamos a ver a continuación son la caja de herramientas que hemos creado a partir de la reflexión; herramientas basadas en los principios libertarios que usaremos en nuestro quehacer docente.

\subsubsection{El aula y los alumnos}

Comprendemos el proceso de enseñanza y aprendizaje como una actividad social recíproca donde tanto el alumno como el profesor "son ambos sujetos que procuran conocer", es decir, donde el discente no sólo aprende sino que enseña" (Freire, 1989, p. 23). Para ello, las clases deben nacer de un acto previo del docente de organización, pero esa organización no es otra cosa que una investigación (cf. Freire, 1978, p. 110) sobre su alumnado y los problemas, inquietudes y motivaciones que lo hacen ser como es.

${ }^{2}$ V. el capítulo de la obra; pp. 128-136. 


\subsubsection{La asignatura: Filosofía}

Partimos de la asignatura de filosofía en un aula de 1. ${ }^{\circ}$ de bachillerato, con tres horas semanales, De cara a este proyecto, hemos de tener presente y manifestar las facilidades que otorga esta asignatura. Se trata de una materia que permite, como no lo hace otra, un diálogo constante (Aubert, 2004), así como el tratamiento de contenidos controvertidos y motivadores para los alumnos (política, ética, etc.). Quizás por eso se esté atacando de forma tan explícita a la asignatura ${ }^{3}$, por la posibilidad emancipadora que ofrece al alumnado.

\subsubsection{Los contenidos}

El seguimiento de la legislación educativa es, junto con la evaluación, uno de los impedimentos más importantes-que pueden surgir a la hora de poner en marcha esta propuesta libertaria. Pragmáticamente hablando, la Ley Orgánica para la Mejora de la Calidad Educativa (Ley n. ${ }^{\circ}$, 2013), sea cual sea su sesgo ideológico y dejando fuera toda crítica filosófica que podamos realizar a la misma ${ }^{4}$, es la base sobre la que debemos trabajar. El bloque de contenidos 6 especificado por la legislación en el que se encontraban los alumnos es un bloque que nos dota de una excelente flexibilidad para abordar los problemas. Ese bloque, que se titula "la racionalidad práctica", comprende contenidos tan diversos como la organización política, la ética utilitarista o el pensamiento utópico; así que se trata de un escenario idóneo para la puesta en marcha del método de trabajo que pretendemos. Si este modelo pedagógico supone una crítica, en primer término, a toda la naturaleza social del sistema capitalista en el que estamos inmersos, qué mejor bloque para ponerla en marcha que el bloque filosófico que se encarga de los pensamientos políticos. Sin ir más lejos, la primera sesión donde planteamos a los alumnos la propuesta de trabajo, es una clase que gira (desde el punto de vista de los contenidos) en torno a la noción de contractualismo (Hobbes contra Rousseau) y en torno a la concepción política-filosófica-antropológica del sistema capitalista en cuanto a individualismo competitivo (Adam Smith) en comparación a otros sistemas igualitarios y cooperativos (vg. Kropotkin, Marx, etc.).

\subsubsection{El método dialógico y problematizante de Freire}

El rechazo total del método tradicional o "método bancario", en palabras de Paulo Freire 5 , tiene su antítesis en el trabajo con el método dialógico, "problematizante", donde alumno y docente analizan la realidad de forma crítica a través de los problemas que les incumben (1974, pp. 84-85). Paulo Freire llevó a cabo su labor pedagógica dentro de lo que él mismo llamó "el tercer mundo" (García, 2015, p. 20). Su análisis de la realidad de estos países en vías de desarrollo se inscribe dentro de la corriente de "la dependencia" " 0 "centro-periferia", que acusa directamente de la situación de dichos países tanto a las potencias imperialistas como a las élites económicas nacionales que controlan el devenir de esas poblaciones en connivencia con las primeras. Dentro de ese contexto, Freire entiende la educación como una "acción cultural para la liberación"; es decir, una acción para combatir la alienación (Freire, 1975). Esa acción cultural fue desarrollada por él a través de la necesaria alfabetización del pueblo en lo que él fundó y llamó "círculos culturales", que no

\footnotetext{
3 Algunos docentes entrevistados aportan ideas sobre por qué se quiere expulsar a la filosofía de los itinerarios: "la filosofía ocupa una función esencial, porque nos obliga a pensar sobre la lengua, sobre el bien, sobre la justicia, sobre lo que somos, sobre la verdad"; es una decisión que "no afecta solo a la Filosofía, sino a las asignaturas que ayudan al alumno a crear: a las Artes Plásticas, a la Música". Para otros muchos su expulsión es un ataque contra la cultura y contra el pensamiento crítico (Álvarez, 2015).

${ }^{4}$ Es mucha la bibliografía que hay al respecto, vg. Gimeno (2014) “La LOMCE. ¿Una ley más de educación?”; Díez (2013) "La comercialización de la educación"; Díez (2014) "Una amenaza para la escuela pública: Laicidad, privatización y segregación"; Monarca, Fernández-González, y Piedrahita (2016) Estudio de opinión sobre la LOMCE; Pérez Gómez (2014) "Evaluación externa en la LOMCE. Reválidas, exclusión y competitividad". Por último, para un análisis exhaustivo de dicha legislación acudir a Asociación "Soy Pública" (2013) “Anteproyecto de la LOMCE analizado".

${ }^{5}$ Otras de las novedades de este trabajo es la inclusión de Paulo Freire en la categoría de pedagogo libertario. Si bien en sus trabajos queda patente, incluso en los propios títulos de las obras, el carácter liberador de su práctica, dentro de la bibliografía secundaria dedicada a la pedagogía libertaria, su nombre aparece sólo en algunos casos y a través de pequeñas citas. No obstante, existen razones más que de sobra para otorgarle esa taxonomización.

6 Para conocer profundamente el análisis de la historia de Latinoamérica desde el punto de vista de la teoría de la dependencia, v. la obra de Eduardo Galeano Las venas abiertas de América Latina (2009).
} 
eran sino espacios en los que se reunían grupos para alfabetizarse mientras aprendían a leer el mundo (García Gómez, 2015: 27). Dicho de otro modo, la enseñanza, es concebida aquí como un "acto político" (Freire, 1989: 13) de debate bidireccional; el modelo profesor transmisor y alumno receptor queda fuera de lugar. Freire explica el porqué de forma muy clarividente cuando afirma que "en la educación colonial, el educador nos transmitía "su" conocimiento, y nuestro papel era el de quien debiera "comer" aquel conocimiento que falsificaba nuestra realidad en función de los intereses de los colonizadores" (Ibíd., p. 15). Resumiendo, Freire quiere realizar un fuerte distanciamiento con respecto a la educación tradicional, instructiva o "educación bancaria". Por ello, el autor utiliza dos nuevos conceptos o términos: i) en lugar de escuelas de adultos, tal y como eran y son conocidas, Freire habla de "círculos de cultura", puesto que esa nueva acción cultural educativa difiere de otras anteriores por sus pretensiones de liberación de la comunidad que participa; y ii) en lugar de docentes o profesores, el pedagogo brasileño usa el concepto de animador o animador cultural, puesto que ese docente no es ya sólo el profesor sino que es además un educador-educando (Ibíd., p. 17) que desarrolla su potencial y aprende junto con los alfabetizandos.

Con el fin de hacer más clara la posterior adaptación que llevaremos a cabo en nuestra propuesta, vamos a explicar, de forma somera, la tarea y metodologías puestas en marcha por Freire en las pequeñas poblaciones agrarias de Brasil tomando como pretexto la necesaria alfabetización de esas sociedades. Las reuniones o "círculos de cultura" comienzan su trabajo a partir de una "palabra generadora, una palabra escogida que pueda ser descompuesta en sílabas para formar otras palabras" (Ibíd., p. 21); no olvidemos que este trabajo (en su contexto) es una labor de alfabetización. Esas palabras generadoras son propuestas al grupo por el animador, que debe fomentar en ellos la participación para crear nuevas palabras a partir de las sílabas descompuestas. Esas palabras generadoras, además, "están siempre asociadas a ciertos temas, que deben ser discutidos en los círculos" (p. 22). Esos temas son, principalmente dos: los problemas económicos y sociales de la producción, y la salud 7 . La formulación de la palabra generadora sería la primera parte de la acción; la segunda y tercera son la codificación y la descodificación (cf. p. 24-27). La codificación es la asociación de una imagen a la palabra generadora o a las palabras surgidas de ella; es decir, si la palabra es «banana»", la codificación sería la asimilación de la palabra a la imagen de una banana. La última de las tres partes del método sería la "codificación"; en ella, tanto educador como educando comienzan, a través del diálogo y el debate, a "leer la realidad" (p. 27) que envuelve al concepto o a la palabra. Si el ejemplo es, siguiendo con el anterior, la «banana», el docente debe motivar un debate, por ejemplo, en torno a los problemas de la producción de ésta o sobre los necesarios aportes proteínicos de los alimentos. En esa conversación abierta iniciada con el pretexto de la alfabetización, se inicia la verdadera acción cultural liberadora, puesto que tanto los alumnos como el profesor toman, a través de ese diálogo, conciencia de su alienación y de sus necesidades.

\subsubsection{La adaptación del método}

La adaptación de la propuesta de Freire como metodología para el trabajo parte de ese concepto de "palabra generadora", pero en este caso, hablaremos de "preguntas generadoras"; es decir, las comienzan con una pregunta que el docente debe realizar con el fin de iniciar un debate que tenga que ver tanto con los contenidos de la asignatura como con los problemas sociales y existenciales cercanos a los propios alumnos (algo que facilita el temario de la asignatura). A partir de la pregunta, y dialogando abiertamente sin jerarquía, vamos descodificando o deconstruyendo el concepto o término que se pone en cuestión con el fin de extraer significados para la realidad social e individual de los individuos. Como botón de muestra, en una de las sesiones se planteó a los alumnos la pregunta «ia quién le gusta estudiar en el instituto?». A partir de ella, los alumnos comenzaron por opinar libremente explicando por qué les gustaba o no les gustaba. El debate prosiguió con una crítica durísima de una gran parte de ellos y ellas a todo lo que tiene que ver con la práctica en el instituto: exámenes, exceso de contenidos, inutilidad de los contenidos, aburrimiento. En cuanto al docente, si el papel del animador en el método dialógico de Freire era fomentar que los alumnos

${ }^{7}$ Los alumnos que acuden a los círculos eran trabajadores de poblaciones deprimidas económicamente que, en la mayoría de los casos, tenían problemas de nutrición y de salud asociados a la pobreza.

${ }^{8}$ En su obra, Freire utiliza para explicar su método la palabra generadora de «matabala», la planta del banano. 
crearan nuevas palabras e iniciaran un debate, en este caso, el profesor debe impulsarlos a ir más allá de las preguntas y los conceptos deconstruyéndolos para desvelar qué se esconde detrás de cada cosa, bajo qué discursos se engloban y qué intereses hay en ello. Dicho de otro modo, ¿qué trama9 quien nos ha impuesto una forma u otra de hacer las cosas? El docente da el protagonismo a los alumnos y se limita a guiarlos ejerciendo, si hiciera falta, una autoridad positiva basada en la ausencia de miedo del alumno a realizar réplica.

\subsubsection{La organización espacial y temporal}

Como consecuencia del intento de ruptura con las líneas generales de la pedagogía tradicional que intenta este trabajo, existen una serie de elementos que deben ser puestos en tela de juicio por su clara alineación con esa práctica de la que pretendemos huir. Dos de esos elementos son el papel del docente, del que ya hemos hablado, y la organización del espacio; y es que ambas establecen una relación de necesidad para mantener el orden jerárquico de una clase magistral unilateral. Como sabemos, un aula se organiza en torno a filas (muchas veces de forma individual) que miran, a través de una perspectiva de contrapicado ${ }^{10}$, dándose la espalda, hacia el profesor (detentador del saber) y adalid del proceso de enseñanza, creando un aura de sabiduría incuestionable, endiosada incluso, en torno a él. Nuestra concepción de la práctica, sin embargo, entiende la práctica de otra manera: el docente puede aprender de los alumnos y debe intentarlo. Por ello, hemos de romper con los conceptos, con todo lo que tenga que ver con esa interpretación de la educación unidireccional. Previa reflexión sobre el porqué, debemos cambiar la organización del aula y nuestra posición dentro de ella. La bien asimilada epistemología del poder y la autoridad provocará que, pese al cambio, sigan manteniendo alguna reticencia a hablar como iguales, pero hemos de ser coherentes en todo lo que propongamos.

\subsubsection{La asamblea}

Ese cambio en el espacio favorece el funcionamiento de la piedra angular de nuestra propuesta libertaria: la asamblea; en ella "surge la espontaneidad, la libertad y la comunicación libre entre las personas" (Paideia, 2017, s/p) 11. Si uno de los principios pedagógicos que enumerábamos en nuestra investigación era la autogestión, ésta solo es posible a través de una asamblea donde todos tienen voz y son partícipes de las decisiones. En ella se debe poner en juicio todo lo que nos rodea, debatiendo en libertad y llegando a la raíz de los problemas y las situaciones que se presenten.

\subsubsection{El juego}

El funcionamiento de la asamblea como eje central de la práctica favorece otro tipo de prácticas que ayudan a crear ambientes positivos de trabajo; el juego es uno de ellos. En su obra La gaya ciencia (2001), Friedrich Nietzsche nos habló de otro tipo de saber, de ciencia, un saber divertido, alegre, que celebra la vida. El juego puede ser una fórmula muy productiva para desarrollar y fomentar la reflexión, así como "la solidaridad, el trabajo cooperativo, la socialización y el ambiente positivo, alegre y sincero" (Paideia, 2017, s/p). Asimismo, un juego puede sustituir a nuestra pregunta generadora, iniciando, a partir de éste, un intenso debate. Esos juegos pueden ser de diversa naturaleza: verbigracia, un falso juicio ético (vg. Juicios de Núremberg), un juego de toma de decisiones, un dilema ético, un juego de rol, etc. En una de las sesiones, se inició la actividad dialógica a través de un juego titulado Smith vs Kropotkin ( $(\mathbb{S}$ ). La intervención del docente se limitó

\footnotetext{
${ }^{9}$ Esa pregunta ha sido utilizada más de una vez en las sesiones para animar a los alumnos a reflexionar. Esta expresión, aplicada a la filosofía, ha sido extraída de una serie de televisión (muy filosófica) titulada Rectify (2013), en la que el protagonista, hablando del bien y del mal y refiriéndose al filósofo griego Platón, dice: «algo tramaba Platón, ¿qué tramaba?».

${ }^{10}$ Un término cinematográfico que se refiere a los planos. En el cine, el plano "contrapicado" es utilizado por los directores para colocar a un sujeto en situación de superioridad o inferioridad (Gubern, 2014). Este autor explica de forma ilustrativa las connotaciones psicológicas de esta percepción.

${ }^{11}$ Esta cita está extraída del manifiesto pedagógico de la Escuela Libre Paideia, una escuela libertaria fundada en 1978 que se encuentra en Mérida, España. La escuela Paideia sigue funcionando en la actualidad, a pesar de los grandes problemas económicos que ha tenido que superar para seguir en marcha. Su gran ideal es lo que ellos llaman "la ética anarquista" que conjuga la potencialidad individual y colectiva (Cuevas, 2003, pp. 141-143).
} 
simplemente a explicar el juego y ejercer de mediador durante su transcurso. Cuando acabó el juego (tan solo duró unos 15 minutos) los alumnos prosiguieron con el debate y el diálogo por su cuenta durante el resto de la sesión.

\subsubsection{La evaluación}

Aquí encontramos la otra gran piedra en el camino (junto con el aglutinamiento de contenidos) para poner en marcha nuestra propuesta pedagógica libertaria. De acuerdo con la manera de este trabajo de entender la praxis, una evaluación unidireccional es del todo injusta y premeditadamente opresiva para el alumnado. Como bien dijo Michel Foucault, la evaluación y los exámenes no sirven sino para establecer rígidos patrones de normalización de la conducta y la personalidad. Es decir, sometiendo a los alumnos a exámenes y pruebas estandarizadas, lo que persigue el sistema educativo es crear un patrón "normalizado" (Foucault, 1988) de conducta y habilidades. Un examen premia la capacidad de reproducir la información del alumnado y establece un ranking sobre aquellos que mejor la reproducen en un examen poniendo en marcha un solo tipo de habilidad o pensamiento simple. Además, como bien indican Díaz y García (1980), de acuerdo con los presupuestos de Piaget - constructivistas - nadie es poseedor absoluto del conocimiento y nunca puede ser un experto total en la materia; de modo que nadie tiene la potestad de evaluar al resto desde una posición de poder (p. 85). En resumen, uno de los objetivos principales de esta propuesta es el de conseguir eliminar de la evaluación esas cuatro finalidades de carácter opresor - necesarias para el mantenimiento del sistema actual- que tan bien explica Fernández Sierra (1996): su finalidad "coercitiva", "punitiva", "defensiva-ofensiva" (demostrar que su asignatura es importante con respecto a otras), y "de demostración de autoridad" (pp. 95-96). Teniendo en cuenta lo dicho, se nos plantea el dilema de la evaluación, discusión que afrontamos en el aula durante la primera sesión. La planificación del debate nos permitió relacionarlo con los contenidos y fomentar la libre discusión y la toma de decisiones de la asamblea. Así, se acordó de manera unánime establecer un sistema alternativo de evaluación que se dividió en tres partes:

1. La elaboración de un sistema sumativo-colaborativo y dialogado acordado por unanimidad mediante asamblea ${ }^{12}$.

2. La autoevaluación como parte de un enfoque curricular "crítico emancipador" (Fernández y Lázaro, 1998). Este enfoque entiende el currículum como un proceso de reflexión y acción colectiva y cooperativa de los distintos estamentos de la comunidad educativa.

3. El desarrollo de un dilema ético con una coevaluación reflexiva donde todos los presentes en el aula intervienen en el proceso de manera constructiva.

\subsection{El desarrollo y análisis crítico de la propuesta en el centro}

\subsubsection{Matriz de la Unidad Didáctica}

Tabla 1

\begin{tabular}{ll}
\hline & Sesión 1 \\
\hline Preguntas generadoras & $-\quad$ ¿A quién le parecen útiles los exámenes? \\
& $\begin{array}{l}\text { JQué son? } \\
\text { Juego: Smith Vs Kropotkin }\end{array}$ \\
\hline $\begin{array}{l}\text { Principios de } \\
\text { procedimiento }\end{array}$ & El Estado, el control y los exámenes \\
\hline $\begin{array}{l}\text { Contenidos } \\
\text { transversales (bloque 1) }\end{array}$ & $\begin{array}{l}\text { Composición escrita de argumentos de reflexión filosófica y de discursos orales, manejando } \\
\text { las reglas básicas de la retórica y la argumentación. 2. Argumentar y razonar los propios } \\
\text { puntos de vista sobre las temáticas estudiadas en la unidad, de forma oral y escrita, con } \\
\text { claridad y coherencia. }\end{array}$ \\
\hline
\end{tabular}

${ }^{12} \mathrm{~V}$. Anexo A donde se explica detalladamente el sistema de evaluación y sus connotaciones filosóficas, así como los contenidos y las competencias que se trabajan a través de su implantación. 


\begin{tabular}{ll}
\hline $\begin{array}{l}\text { Contenidos (bloque 6) } \\
\text { que deben surgir }\end{array}$ & $\begin{array}{l}\text { El contractualismo: Hobbes, Locke, Rousseau y Montesquieu. Los fundamentos filosóficos } \\
\text { del capitalismo. La función del pensamiento utópico. }\end{array}$ \\
\hline $\begin{array}{l}\text { Criterios de evaluación } \\
\text { (Bloque 6) }\end{array}$ & $\begin{array}{l}\text { 4. Explicar la función, características y principales interrogantes de la Filosofía política, } \\
\text { como el origen y legitimidad del Estado, las relaciones individuo-Estado o la naturaleza de } \\
\text { las leyes. }\end{array}$ \\
\hline $\begin{array}{l}\text { Estándares de } \\
\text { aprendizaje evaluables } \\
\text { (Bloque 6) }\end{array}$ & $\begin{array}{l}\text { 4.1 Identifica la función, características y principales interrogantes de la Filosofía política. } \\
\text { 4.2 Utiliza con rigor conceptos como democracia, Estado, justicia, Derecho, derechos } \\
\text { naturales, Estado democrático y de derecho, legalidad, legitimidad, convención, } \\
\text { contractualismo, alienación, ideología, utopía, entre otros conceptos clave de la filosofía } \\
\text { política. }\end{array}$ \\
\hline Competencias & CAA, CCL, CEC. \\
\hline
\end{tabular}

Fuente. Elaboración propia.

\subsubsection{Sesión expositiva}

Contextualicemos lo máximo posible teniendo en cuenta la protección de datos de los alumnos y del centro. Nos encontramos en Almería, en un instituto de educación pública en el año 2017. La sesión se inició con una pequeña introducción a las pretensiones filosóficas de la propuesta global de Unidad Didáctica. Comencé ${ }^{13}$ poniendo especial énfasis en que las clases debían basarse en varios puntos: 1) la libertad de expresión y participación a través del diálogo y el debate abierto sin jerarquía; 2) la proposición de alternativas por parte de todos los asistentes a la sesión; 3) la colaboración entre todos los asistentes; 4) la ausencia de exámenes y de calificación unilateral; 5) la toma de decisiones a partir de la asamblea de aula. Gran parte de los alumnos parecían intrigados por el inicio de la sesión; a dos alumnas y un alumno de la clase que son lectores habituales de lecturas izquierdistas como Marx o Bakunin, les entusiasmó ese comienzo. Los alumnos de otro grupo, que se sienta al fondo de clase, son bastante subversivos en sus pensamientos y a lo largo de esta primera sesión lo hicieron notar de forma notable en sus manifestaciones contra el sistema y la forma de dar clase.

Tras la pequeña charla propedéutica, nos sentamos en el suelo del aula en círculo, para romper el espacio habitual, y les planteé la pregunta generadora con la que daba comienzo el debate: ¿A quién le gustan los exámenes? ¿A quién le parecen útiles? ¿Qué son en realidad? Los alumnos llegaron a la conclusión de que los exámenes son una forma de clasificación (buenos y malos), algo por lo que llegaban incluso a indignarse, concretamente una alumna de la primera fila. A la vez que iban planteando ideas, yo mismo iba participando aportándoles filósofos y pensadores que se relacionaban con esos contenidos. En este caso, hablamos sobre todo de Michel Foucault, un filósofo al que ya conocían de temas anteriores, aunque no recordaban mucho qué decía en sus obras; una nueva muestra de que aprobar un examen no es aprender. También surgió otro pequeño debate, propuesto por una alumna a quien le di un impulso para que propusiera el tema de discusión: la competitividad. Esa alumna a la que he aludido anteriormente, que se declaró marxista, expresó que la necesidad del sistema de mantenernos enemistados es una cosa que se fomenta con los exámenes y con el salario asociado al trabajo. Tengo que decir que esta alumna tiene un poder para la retórica muy especial y, en ocasiones, apabullaba a algunos de sus compañeros. Mi labor consistía en intentar mediar para que todos participaran y, aunque algunos alumnos no realizaban demasiadas aportaciones, la gran mayoría expresó su opinión en varias ocasiones. Otro grupo de alumnos más pragmáticos (tres alumnas y otros dos compañeros que suelen sentarse en la zona media de la clase pegados a las ventanas) insistían en que la aglomeración de exámenes los dejaba sin tiempo libre. Personalmente, estas opiniones me llevaron a una constatación a la que llevo tiempo dando vueltas: los alumnos no están adormilados, sino que están saturados. Su actitud me recuerda a una gran cita que leí hace tiempo en un libro cuyo título no recuerdo, que dice: "amo la literatura a pesar de mi profesor de literatura". En otras palabras, la sobrecarga de tareas y estudios hace que los alumnos, incluso desde edades mucho más tempranas, acaben desarrollado una respuesta condicionada negativa hacia los libros. Es más, estoy convencido de que el agotamiento

${ }^{13}$ La narración de las sesiones, dado el carácter vivencial con el que se pretende explicarlas, se realizará en primera persona. Con ello, se busca aligerar la lectura y hacerla más comprensible. 
del tiempo de estudio los invalida para realizar otras actividades artísticas de iniciativa personal para las cuales poseen un gran potencial sin desarrollar.

Una vez se había relajado un poco ese debate en torno a los exámenes, les planteé otra pregunta: si debemos evaluar (algo que no es malo ${ }^{14}$, porque nos permite comprobar nuestro avance como grupo), ¿cómo podemos hacerlo? Las ideas surgieron rápidamente: la coevaluación y la autoevaluación. La asamblea acordó realizar parte de ella de esa manera, la otra parte de la evaluación (la parte sumativa-colaborativa) surgió y se aprobó más tarde.

La segunda parte de la sesión, en lugar de partir de una pregunta generadora, se inició a través de un juego que yo mismo he titulado Adam Smith VS Kropotkin ${ }^{15}$ y que vincula contenidos de filosofía política con la evaluación y las relaciones entre los alumnos. Este juego ya lo había puesto en marcha en otras dinámicas de grupo, pero esta clase me sorprendió gratamente. De las 7 rondas totales de las que consta el juego, en tres ocasiones, los cuatro grupos sacaron la cartulina roja que resta puntos a la banca y los da a todos los compañeros. Asimismo, uno de los grupos (donde curiosamente se encontraban las dos alumnas que leían a Marx) sacó las 7 veces cartulina roja. Las conclusiones que surgieron en el debate posterior fueron rotundas: es mejor trabajar cooperativamente que competitivamente (Apoyo Mutuo vs Competencia Capitalista ${ }^{16}$ ). Los contenidos que debían surgir eran, principalmente, contenidos sobre filosofía política y tipos de contrato social: ¿el ser humano quiere su bien propio a costa de los demás o es un ser predispuesto al apoyo mutuo? La mayoría mantenía una postura hobbesiana, pero intenté hacerles reflexionar comentándoles las tres ocasiones en que habían levantado el cartel rojo.

En ese punto de la clase, les planteé la discusión y propuesta para aprobación del grupo de una tercera forma de evaluar la Unidad Didáctica: el sistema sumativo-colaborativo ${ }^{17}$. La filosofía fue una sugerencia mía, pero la rúbrica fue elaborada por la asamblea y debía ser aprobada por todos los alumnos del aula. En caso contrario, deberían buscar una alternativa para los alumnos que no estuvieran de acuerdo o directamente rechazar la sugerencia. Todos los alumnos aceptaron, algo que no me esperaba; como proyecto es algo realmente interesante. Los alumnos respondieron de manera excepcional en todos los aspectos, fue la mejor clase de todas las realizadas. La novedad en la metodología y el nuevo sistema de evaluación llamó mucho su atención. Como apunte, varios alumnos y alumnas advirtieron que ese sistema iba a traer algunas disputas entre el alumnado, algo que también se debatió en los últimos momentos de la sesión. No obstante, como he dicho, todos aceptaron. En páginas posteriores veremos cómo trabajaron y si cumplieron los objetivos, pero adelanto que las tareas que acordamos realizar todos - yo me comprometí, intentando mostrar ejemplaridad, a realizar las mismas tareas que ellos - fueron un debate individual de un minuto (que sumaría o restaría para el cómputo global de la clase) y una reflexión sobre un dilema o juicio ético.

\section{Conclusiones}

Durante este apartado de conclusiones nos vamos a ocupar principalmente de dos aspectos: por un lado, evaluar si hemos conseguido los objetivos propuestos cuando se inició la investigación teórica y el planteamiento de los problemas educativos a los que queríamos hacer frente. Por otro lado, es imprescindible señalar, con el fin de mejorar nuestra labor, las limitaciones inherentes a la propuesta y cómo subsanarlas en la medida de lo posible.

Hemos hablado de las relaciones dentro del aula; todos sabemos que en la enseñanza dentro del bachillerato premia la pedagogía instructiva donde el proceso de enseñanza y aprendizaje se convierte en una comunicación unilateral del docente hacia el discente, que recibe y reproduce una información la mayoría de las veces de forma acrítica. El planteamiento de preguntas y juegos

\footnotetext{
${ }^{14}$ Friedrich Nietzsche dijo que evaluar es medir o interpretar nuestros actos, nuestra vida.; algo que nos permite evolucionar como seres (Cf. Deleuze, 2000, p. 45).

15 V. Anexo B, donde desarrollamos la actividad: Smith VS Kropotkin.

16 Para conocer más sobre los contenidos filosóficos, v. Kropotkin (2009) y Smith (2007).

17 V. Anexo A.
} 
generadores, así como el establecimiento de una asamblea para la toma de decisiones —algo que sí que se suele desarrollar en otras etapas educativas-, limita el papel del docente y acentúa la responsabilidad de los alumnos en sus clases. Los alumnos, en contra de lo que piensa la tecnocracia encargada de gestionar sus vidas, son personas con un gran interés por desarrollarse en múltiples facetas que tenemos que ayudarles a descubrir. A todos les gusta debatir y confrontar ideas y, si se les da la oportunidad, hacen gala de argumentos e ideas refrescantes y utópicas. Durante las clases que han conformado esta unidad didáctica libertaria, una gran parte de los numerosos alumnos que componían el curso han demostrado de forma clara capacidades para la autogestión, la discusión asertiva y respetuosa, autonomía, trabajo colaborativo, pensamiento crítico y nihilista con todo lo que les rodea y además, en las tareas pactadas, una gran cantidad de conocimientos interiorizados.

Por otro lado, y con esto terminamos, las limitaciones de la propuesta tienen que ver con la atención a la diversidad. Es decir, un planteamiento basado en el debate puede dejar de lado a alumnos a los que les cueste expresarse en público o que posean una personalidad no tan fuerte como para discutir abiertamente frente a 35 personas. No obstante, cuando ciertos alumnos no son capaces de adaptarse a los simples exámenes repetitivos se habla del fracaso o de incompetencia de los alumnos. Las habilidades de expresión y discusión de ideas son elementos imprescindibles y significativos para la futura vida en sociedad. Lo quieran algunos o no, discutir y expresar las propias ideas con claridad y fuerza son capacidades muchos más funcionales para sus vidas que memorizar fechas y fórmulas matemáticas. Claro está, el papel del docente, aún intentando que se note lo menos posible, debe velar porque todos los alumnos sean partícipes del proyecto y de la asamblea incentivando su participación y haciéndoles saber que, contra lo que les dicen día a día, sus opiniones son muy valiosas y sus ideas son necesarias para un mundo mejor, para una utopía.

\section{Referencias}

Álvarez, P. (5 de octubre 2015). Platón, expulsado de clase. El País. Recuperado de http://politica.elpais.com/politica/2015/10/02/actualidad/1443800282_346551.html.

Asociación "Soy Pública" (2013). Anteproyecto de la LOMCE analizado. Recuperado de https:/ / soypublica.wordpress.com/2012/10/08/lo-que-esconde-la-lomce-analisis-delanteproyecto-de-ley-de-educacion/.

Aubert, D. (2004). Dialogar y transformar: pedagogía crítica del siglo XXI. Barcelona: Graó.

Bakunin, M. (1979). La instrucción integral. Mallorca: J. de Olañeta ed.

Cappelletti, A. (2010). La ideología anarquista. Barcelona: El grillo libertario.

Cappelletti, A. (1978). El pensamiento de Kropotkin: ciencia, ética y anarquia. Madrid: Zero.

Cuevas, F. (2003). Anarquismo y educación. Madrid: Fundación de Estudios Libertarios.

Deleuze, G. (2000). Nietzsche. Madrid. Arena.

Díaz, C. \& García, F. (1980). Ensayos de pedagogía libertaria. Madrid: Zero.

Díez, E. (2013). La comercialización de la educación. Revista Tempora, 16, pp. 59-69.

Díez, E. (2014). Una amenaza para la escuela pública: Laicidad, privatización y segregación. Revista Interuniversitaria de Formación del Profesorado, 28(3), pp. 105-117.

Fernández Sierra, J. (1996). ¿Evaluación? No, gracias, calificación. Cuadernos pedagógicos, 243, pp. $92-$ 97.

Fernández, S \& Lázaro, M. N. (1998). Los enfoques curriculares en la formación del profesorado. Perspectiva educacional, 31(2), pp. 77-84.

Ferrer i Guárdia, F. (2009). La Escuela Moderna. Barcelona: Tusquets.

Foucault, M. (1980). Microfísica del poder. Madrid: Ed. LP.

Foucault, M. (1988). Arqueología del saber. México D.F.: Siglo XXI.

Freire, P. \& Illich, I. (1975). La desmitificación de la conciencia y otros escritos. Bogotá: Editorial América Latina.

Freire, P. (1974). Concientización. Buenos Aires: Búsqueda.

Freire, P. (1978). Pedagogia y acción liberadora. Madrid: Zero.

Freire, P. (1989). Cartas a los alfabetizadores. Quito: CEDECO.

Galeano, E. (2009). Las venas abiertas de América Latina. México: Siglo XXI. 
Gallo, S. (1997). El paradigma anarquista de educación. Semillas de Libertad. Plataforma ácrata digital. Recuperado de http://www.f1yingmind.com/plataforma/doc7.

García Moriyón, F. (1982). Pensamiento anarquista español. Individuo y colectividad (Tesis Doctoral). Universidad Complutense, Madrid.

García, T. (2015). Paulo Freire. Pedagogía liberadora. Madrid: Catarata.

Gimeno, J. et al. (2013). Por otra politica educativa. Sevilla: Ediciones Morata.

Gimeno, J. (2014). La LOMCE. ¿Una ley más de educación?. Revista Interuniversitaria de Formación del Profesorado, n. ${ }^{\circ}$ 28(3), pp. 31-44.

Godwin, W. (2005). Justicia política [en línea]. Recuperado de http://www.antorcha.net /biblioteca_virtual/politica/godwin/caratula.html.

Gubern, R. (2014). Historia del cine. Madrid: Anagrama.

Kropotkin, P. (2009). La selección natural y el Apoyo Mutuo. Madrid: CSIC.

McKinnon, R. (Creador). (2013). Rectify [Serie TV]. USA: SundanceTV / Gran Via Productions / Zip Works.

Nietzsche, F. (2001). La Gaya ciencia. Madrid: Akal.

Paideia, Escuela libre. (2017). Paideia-Pedagogia. Recuperado de http://www. paideiaescuelalibre.org/somos/10-pedagogia.html.

Paniagua, J. (2008). La larga marcha hacia la anarquia. Madrid: Síntesis.

Pérez, A. (2014). Evaluación externa en la LOMCE. Reválidas, exclusión y competitividad. Revista interuniversitaria de formación del profesorado, 81, pp. 59-72.

Real Decreto 1105/2014, de 26 de diciembre, por el que se establece el currículo básico de la Educación Secundaria Obligatoria y del Bachillerato. Boletín Oficial del Estado. Madrid, 3 de enero de 2015, n. 3 , pp. 169 a 546.

Smith, A. (2007). La riqueza de las naciones. Madrid: Alianza.

Tomassi, T. (1978). Ideología libertaria y educación. Madrid: Campo abierto.

\section{Anexo A. Propuesta innovadora: evaluación sumativo-colaborativa}

Una vez han reflexionado sobre el papel de la calificación en la enseñanza dentro del sistema capitalista, planteamos un sistema alternativo de evaluación. En primer lugar, todos los alumnos deben participar y, en el caso de que uno no quiera, todos, mediante asamblea, deben tomar la decisión. Se trata de un sistema de evaluación basado en la máxima de Kropotkin (2009) "de cada cual su capacidad, a cada cual su necesidad". Todos suman y todos restan. En este proyecto, se consigue una evaluación comunitaria, colectiva. Todos deben trabajar para todos. Es decir, en cada actividad o elemento que se incluya en la rúbrica, cada alumno que haga la tarea sumará para el resto, y todo el que no la haga resta al cómputo global.

Este planteamiento necesita de una asamblea en libertad de expresión. Asimismo, se generará un intenso debate sobre la naturaleza humana del trabajo, por lo que podremos incluir contenidos que tengan que ver con ese bloque 6 de filosofía política. También precisaremos de debate abierto para determinar la rúbrica a utilizar; en el caso de nuestra clase surgió esta:

\begin{tabular}{|r|l|r|l|}
\hline \multicolumn{2}{|l|}{ LO QUE SUMA } & \multicolumn{2}{l|}{ LO QUE RESTA } \\
\hline 20 & Discurso & -30 & No hacer discurso \\
\hline 15 & Trabajo extra & & \\
\hline 5 & Buena participación & -5 & Escasa participación \\
\hline 30 & Comentario ético & -40 & No hacer proyecto estético \\
\hline & & -1 & Asistencia injustificada \\
\hline & & -5 & Retraso \\
\hline & & -50 & Plagio en un trabajo \\
\hline
\end{tabular}

Trabajos extra:

- Quitter 
- Dibujo

- Mini-Ensayo

- Poesía

- Fotografía filosófica

- Cortometraje

\section{Anexo B. Juego: Smith vs Kropotkin}

Desarrollo: La actividad consta de 3 partes.

1) Una primera parte de introducción y contenidos filosóficos, donde hablamos, en primer lugar, de Rousseau ("el hombre es bueno por naturaleza y es la sociedad la que lo corrompe") y Hobbes ("el hombre es un lobo para el hombre") como parte de la concepción filosófica del ser humano. A partir de ahí, hablamos de otras dos concepciones filosófico políticas: Pedro Kropotkin y Adam Smith (Teoría del Apoyo Mutuo y liberalismo competitivo).

2) La segunda parte es el juego en sí, que se desarrolla de la siguiente manera:

1. Se divide la clase en 4 grupos de alumnos que formarán los equipos 1, 2, 3,4. El quinto equipo estará formado por el profesor, que será la banca. A continuación se le repartirá a cada equipo (excepto a la banca) una cartulina azul y otra roja.

2. Una vez hechos los equipos y con las cartulinas en la mano, se les explicará la dinámica. El juego consta de 5 rondas iniciales y dos rondas extra. En cada ronda, a la voz del profesor, el capitán de cada equipo levantará - previo consenso con el resto- una de las dos cartulinas. Sacar una cartulina u otra tiene unas consecuencias explicadas en la siguiente tabla; los puntos que obtendrá cada equipo se determinarán por el color que saquen ellos y el color que saquen los otros equipos:

\begin{tabular}{|c|c|c|c|c|}
\hline $\mathrm{R}$ & $\mathrm{R}$ & $\mathrm{R}$ & $\mathrm{R}$ & -15 PUNTOS PARA TODOS /// 0 PUNTOS PARA LA BANCA \\
\hline & $\mathrm{R}$ & $\mathrm{R}$ & A & $\begin{array}{l}\text {-5 PUNTOS ROJO /// } 25 \text { PUNTOS AZUL /// } 25 \text { PUNTOS LA } \\
\text { BANCA }\end{array}$ \\
\hline 2 & $\mathrm{R}$ & A & $\bar{A}$ & $\begin{array}{l}\text {-5 PUNTOS ROJO /// } 20 \text { PUNTOS AZUL /// } 30 \text { PUNTOS LA } \\
\text { BANCA }\end{array}$ \\
\hline $\mathrm{R}$ & A & A & A & $\begin{array}{l}\text {-10 PUNTOS ROJO /// } 15 \text { PUNTOS AZUL /// } 25 \text { PUNTOS LA } \\
\text { BANCA }\end{array}$ \\
\hline$\overline{\mathrm{A}}$ & $\overline{\mathrm{A}}$ & $\overline{\mathrm{A}}$ & $\overline{\mathrm{A}}$ & -25 PUNTOS AZUL /// 50 PUNTOS LA BANCA \\
\hline
\end{tabular}

3. Después de las 5 rondas iniciales, se reunirán, en un lugar apartado, los cuatro capitanes y la banca para que los capitanes de los cuatro equipos se pongan de acuerdo - si lo ven oportuno- para ver qué color sacan en las dos últimas rondas finales.

4. El equipo que obtenga más puntos gana.

3) La última de las partes del juego, una vez finalizado, constará de/consistirá en un debate donde, casi con toda seguridad, surgirán debates filosóficos en torno a la política y a la concepción filosófica del ser humano. 


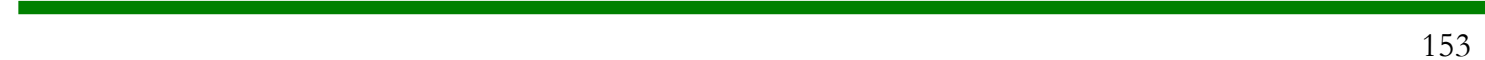

Tendencias Pedagógicas, 33, 2019, pp. 140-153. DOI: 10.15366/tp2019.33.010 